\title{
Tetherins of various species inhibit the release of porcine endogenous retrovirus from human cells
}

\author{
E. H. BAE, Y. T. JUNG* \\ Department of Microbiology, Dankook University, Cheonan 330-714, Korea
}

Received May 13, 2013; accepted February 24, 2014

\begin{abstract}
Summary. - Pigs are considered as suitable xenotransplantation organ donors. However, the risk of pathogen transmission from pigs to human is a major concern in the transplantation of porcine tissues since it had been shown that porcine endogenous retroviruses (PERVs) can infect human cells. Tetherin has recently been described as a host restriction factor that blocks the release of virus particles from cells infected with some enveloped viruses. We compared tetherins derived from various species in their activity against PERVs by using a pseudotype assay. The results showed that (i) mammalian tetherins inhibit spread of PERVs, (ii) murine and rhesus tetherins are weaker inhibitors than canine and feline ones, (iii) human tetherin is induced by interferon alpha (IFN- $\alpha$ ) and (iv) IFN- $\alpha$ treatment of 293T-PERV-PK-CIRCE cells reduced PERV release. We conclude that transgenic overexpression of tetherin combined with its induction by IFN- $\alpha$ may reduce the risk of PERV dissemination in xenotransplantation.
\end{abstract}

Keywords: interferon; porcine endogenous retroviruses; tetherins; xenotransplantation

\section{Introduction}

Porcine endogenous retroviruses (PERVs) present a unique concern associated with xenotransplantation because they have been shown to infect certain human cells in vitro. Two classes of infectious human-tropic replicationcompetent PERVs (polytropic PERV-A and PERV-B) and one class of ecotropic PERV-C have been identified (Boneva et al., 2001; Magre et al., 2003); the potential for recombination between ecotropic PERV-C and human-tropic PERV-A and PERV-B adds an additional level of infection risk. PERVs are integrated into the genome of all pigs; therefore, the removal of all PERV-related sequences by knockout technology or selective breeding is very unlikely. Several strategies have been proposed and could potentially be employed to

"Corresponding author. E-mail: yjung@dankook.ac.kr; phone: +82-41-550-3453.

Abbreviations: GP = glycoprotein; $\mathrm{HA}=$ hemagglutinin; $\mathrm{HIV}=$ human immunodeficiency virus; IFN = interferon; PERV = porcine endogenous retrovirus; SIV = simian immunodeficiency virus; $\mathrm{TM}=$ transmembrane domain reduce PERV transmission, such as transgenic pigs expressing siRNAs, the use of restriction factor human APOBEC3G and single domain antibodies directed against PERV Gag (Dieckhoff et al., 2007; Jonsson et al., 2007).

PERV s were released from porcine cell lines including pig kidney cell lines PK15, MPK, and mitogenically-activated peripheral blood mononuclear cells (PBMC). PERVs are classified as endogenous viruses of the family Retroviridae and the genus Gammaretrovirus; additionally, they are related closely to mammalian type- $C$ retroviruses, such as the gibbon-ape leukemia virus and the murine leukemia virus (Magre et al., 2003).

During evolution the host has developed a variety of "restriction factors" to fight retroviral infections (Harris et al., 2004; Nakayama et al., 2010). Restriction factors are components of the innate immune system and act at diverse steps in retroviral replication. Tetherin (also referred to as BST-2 or CD317) is an antiviral cellular restriction factor that blocks the release of particles of many enveloped viruses, including retroviruses (HIV-1, HIV-2, SIV, MLV, and XMRV (xenotropic murine leukaemia virus-related virus)), filoviruses (Ebola virus and Marburg virus), arenavirus (Lassa 
virus) and herpesvirus (Dietrich et al., 2011; Mattiuzzo et al., 2010; Neil et al., 2008; Perez-Caballero et al., 2009; Radoshitzky et al., 2010; Zhang et al., 2010). It was first identified as a cellular restriction factor that blocks the release of HIV. Tetherin is a $30-36 \mathrm{kDa}$ type II transmembrane protein and its expression is induced by IFN-a (Neil et al., 2007). The sequence identities of tetherin among different primate species are relatively low. Tetherin consists of 4 domains, an N-terminal cytoplasmic tail (CT), a single transmembrane domain (TM), an extracellular coiled-coil domain, and a Cterminal glycosyl phosphatidylinositol (GPI) anchor. The extracellular domain of tetherin forms stable cysteine-linked homodimers and is modified by N-linked glycosylation (Le Tortorec et al., 2011; Zhang et al., 2010). N-terminal TM domain and C-terminal glycosyl phosphatidylinositol anchor of tetherin were reported to be essential for antiviral activity, while N-linked glycosylation was dispensable. Dimerization of tetherin was shown to be essential for inhibition of HIV-1, but not for Lassa and Marburg viruses (Sakuma et al., 2009). Tetherin proteins associated with lipid rafts are found at the plasma membrane and at the trans-Golgi network. Tetherin appears to inhibit virus release by connecting both viral and host cell membranes.

Several viruses have evolved viral-encoded antagonists to overcome tetherin's restriction. HIV-1 Vpu, HIV-2 Env, SIV Nef, KSHV K5, and Ebola GP function as antagonists of tetherin (Jia et al., 2009; Kaletsky et al., 2009; Kirchhoff et al., 2010; Mansouri et al., 2009; Neil et al., 2008). HIV-1 Vpu downregulates tetherin from the cell surface and several studies have reported that Vpu directs the proteasomal degradation of tetherin (Neil et al., 2008). HIV-2 Env protein causes downregulation of tetherin from the cell surface, but Env protein does not cause degradation of tetherin. SIV Nef can antagonize rhesus macaque, pig-tail macaque, or African green monkey tetherin. In addition, SIV Nef downregulates macaque tetherin from the cell surface without affecting the stability of tetherin. The K5 protein of Kaposi's sarcoma- associated herpes virus was shown to reduce the levels of tetherin at the plasma membrane. The Ebola virus GP (glycoprotein) colocalizes with tetherin without removing it from the cell surface. The mechanism by which Ebola virus GP antagonizes the antiviral activity of tetherin remains unclear. However, gammaretroviruses (murine leukemia virus and PERV) do not encode such accessory genes and are not able to overcome tetherin's restriction.

It has been reported that human and porcine tetherin can inhibit PERV release from producer cells (Mattiuzzo et al., 2010). However, tetherin proteins from different species have different sensitivities to various viral countermeasures (Jia et al., 2009; McNatt et al., 2009; Sliva et al., 2012; Viswanathan et al., 2011). Therefore, in this study, we examined the effect of mammalian tetherins of various species on PERV release from PERV-harboring cells.

\section{Materials and Methods}

Cells. The 293T human embryonic kidney (ATCC CRL-11268), 293-PERV-PK-CIRCE (ECACC 97051411; human 293T cells infected with PK15-derived PERVs), PK15 pig kidney (ATCC CCL-33), FRhk (Rhesus monkey), CRFK (Crandell-Rees feline kidney), NIH3T3 and MDCK cells were maintained in DMEM supplemented with $10 \% \mathrm{FCS}, 100 \mathrm{U} / \mathrm{ml}$ penicillin, and $100 \mu \mathrm{g} /$ $\mathrm{ml}$ streptomycin.

Cloning of tetherins. Total RNA was extracted from the 293T human embryonic kidney cells using TRI-Reagent (Molecular Research Center, USA) according to the manufacturer's instructions. Two primer pairs were designed to amplify human tetherin (Table 1). HuTHN-for (nt 10-30), 5'-ACGCGTCGACCATGGCATC TACTTCGTATGAC-3' (SalI site is underlined) and HuTHN-rev (nt 532-552), 5'-CCGCTCGAGTCACTGCAGCAGAGCGCT GAG-3' (XhoI site is underlined) were designed to amplify a $540 \mathrm{nt}$ long coding sequence of tetherin. cDNA synthesis was performed in $20 \mu \mathrm{l}$ volumes using a Random Primer RT PreMix Kit (Intron

Table 1. PCR primers used for cloning of tetherins

\begin{tabular}{|c|c|c|c|c|}
\hline Species & Primer & Sequence & Position (nt) & Acc. Nos \\
\hline Human & $\begin{array}{l}\text { THN-F } \\
\text { THN-R }\end{array}$ & $\begin{array}{l}\text { 5'-ACGCGTCGACCATGGCATCTACTTCGTATGAC-3' } \\
\text { 5'-CCGCTCGAGTCACTGCAGCAGAGCGCTGAG-3' }\end{array}$ & $\begin{array}{l}10-30 \\
532-552\end{array}$ & NM_004335 \\
\hline Rhesus & $\begin{array}{l}\text { THN-F } \\
\text { THN-R }\end{array}$ & $\begin{array}{l}\text { 5'-ATGGCACCTATTTTGTATGACTA-3' } \\
\text { 5'-TCACAGCAGCAGAGCGCTCA-3' }\end{array}$ & $\begin{array}{l}1-23 \\
530-549\end{array}$ & HM_775182 \\
\hline Mouse & $\begin{array}{l}\text { THN-F } \\
\text { THN-R }\end{array}$ & $\begin{array}{l}\text { 5'-CACATGGCGCCCTCTTTCTA-3' } \\
\text { 5'-CCTCAAAAGAGCAGGAACAG-3' }\end{array}$ & $\begin{array}{l}8-27 \\
512-531\end{array}$ & NM_198095 \\
\hline Porcine & $\begin{array}{l}\text { THN-F } \\
\text { THN-R }\end{array}$ & $\begin{array}{l}\text { 5'-ATGTCACCTAGTTTGTATTCC-3' } \\
\text { 5'-AGACCTCAGGTCAGCAG-3' }\end{array}$ & $\begin{array}{l}1-21 \\
523-534\end{array}$ & NM_001161755 \\
\hline Canine & $\begin{array}{l}\text { THN-F } \\
\text { THN-R }\end{array}$ & $\begin{array}{l}\text { 5'-TACATGGCACCTACGCTTTACC-3' } \\
\text { 5'-TCAGGCCAGCAGAGCCCTAA-3' }\end{array}$ & $\begin{array}{l}1-22 \\
551-570\end{array}$ & XM_860510 \\
\hline Feline & $\begin{array}{l}\text { THN-F } \\
\text { THN-R }\end{array}$ & $\begin{array}{l}\text { 5'-ATGGCACCTGCTTTTTACCAC-3' } \\
\text { 5'-TCAGGCCAGCAGAGCAACGA-3' }\end{array}$ & $\begin{array}{l}1-21 \\
542-561\end{array}$ & NM_001243085 \\
\hline
\end{tabular}


Biotechnology, Korea) according to the manufacturer's instructions. The PCR products of the human tetherin were ligated into the pGEM-T Easy Vector System (Promega, USA). The tetherinligated vectors were digested with the restriction enzymes NotI and XhoI. The NotI-XhoI fragment from pGEM-T-tetherin was inserted directly into the same sites of pcDNA3.1(+). C-terminal HA-tagged human tetherin was produced by introducing the PCR product into pcDNA3-mCAT-HA vector using KpnI and XhoI present in the primers. HuTHN-HA-for 5'-GGTACCAT GGCATCTACTTCGTATGAC-3' (KpnI site is underlined) and HuTHN-HA-rev 5'-CTCGAGTTCTGCAGCAGAGCGCTGAG-3' (XhoI site is underlined) were used for RT-PCR. The expression plasmid for human tetherin was named pcDNA3-huTHN-HA. Similarly, the tetherin coding sequence from dog, cat, mouse, pig, and rhesus macaque was amplified using cDNA generated from MDCK, CRFK, NIH3T3, PK15 and FRhk, respectively (Table 1). To generate each tetherin expression vector containing an EGFP, EcoRI-EcoRI fragment of the amplified PCR products was inserted directly into the same sites of pIRES2-EGFP.

Western blot analysis of tetherins. Cell lysates from the pcDNA3THN-HA-transfected 293T cells were prepared 2 days after transfection by lysing the cells in $300 \mu \mathrm{l}$ of mammalian protein extraction reagent lysis buffer. All samples were denatured at $100^{\circ} \mathrm{C}$ for 10 mins and then separated by SDS-PAGE. Proteins were blotted and then probed with anti-HA antibodies (1:200) (Bethyl, USA) for 1 hr or overnight, followed by a 1:5,000 dilution of goat anti-rabbit conjugated HRP antibody (Komabio, Korea) for $1 \mathrm{hr}$. The blots were visualized using DAB.

Assay of PERV-VSV pseudotypes. The pCMV-VSV-G, pVPackPERV-A-GP, and pCLMFG-lacZ (Imgenex Co., USA) were used to construct PERV-VSV pseudotype viruses. To generate the PERV-A gag-pol expressing plasmid pVPack-PERV-A-GP, NotI-HpaI fragments of the amplified PCR products and HpaI-HpaI fragment from PERV full length molecular clone were cloned into the pVPack-Eco (Stratagene, USA). 293T cells were transfected with pCMV-VSV-G, pVPack-PERV-A-GP, pCLMFG-lacZ, and each tetherin expression plasmid using the Qiagen (Qiagen, USA) PolyFect Transfection Kit. Viral supernatants were collected from each transfection culture and were used to infect $293 \mathrm{~T}$ cells that had been plated in 6-well culture dishes at a density of $1.5 \times 10^{5}$ per well. The cells were infected with $1 \mathrm{ml}$ of virus in the presence of $8 \mu \mathrm{g} / \mathrm{ml}$ polybrene for 3 $\mathrm{hrs}$, and $2 \mathrm{ml}$ of fresh medium was then added to each well. Two days after infection, the cells were fixed with $0.5 \%$ glutaraldehyde and stained to reveal the presence of $\beta$-gal activity. Infectious titers were expressed as the blue CFU per ml of virus supernatant.

Real-time RT-PCR assay of PERV release. Virus production from tetherin-transfected 293-PERV-PK-CIRCE was examined by real-time RT-PCR. Total RNA from virion-containing culture supernatants were extracted using TRI-Reagent and eluted with DEPC treated water. The primers PERV-gag-for (5'-TGATCTAGT GAGAGAGGCAGAG-3'), PERV-gag-rev (5'-CGCACACTGGTC CTTGTCG-3') were used. Real-time RT-PCR was conducted using a PrimeScript II 1st strand cDNA Synthesis Kit and a SYBR Premix
Ex Taq II Kit (Takara, Japan). A Thermal Cycler Dice Real Time System (Takara, Japan) was used for the thermal cycling and to record fluorescence changes. Absolute quantification of the virion RNA copy number was performed by using an external homologus standard (Lee et al., 2012). The plasmid pBlu-PERV-A harboring the PERV-A gag was digested with SpeI and used as target in an in vitro transcription performed with a TranscriptAid T7 High Yield Transcription Kit (Fermentas Inc, USA). RNAs were purified and their concentrations were determined by measuring at A260. $C_{\mathrm{T}}$ (threshold) values in each dilution were assayed using real-time RT-PCR to generate standard PERV-A curves. The $C_{\mathrm{T}}$ values were plotted against their initial template copy numbers. The standard curve was used to calculate the precise copy number of specific PERV-A virion RNA.

Real-time RT-PCR assay of human tetherin. To examine the effect of IFN- $\alpha$ treatment on PERV production in 293-PERV-PKCIRCE, 293-PERV-PK-CIRCE cells were treated for $24 \mathrm{hrs}$ in the presence of 250,500 or $1,000 \mathrm{U} / \mathrm{ml}$ IFN- $\alpha$ (Sigma). Total cellular RNA was extracted from pelleted cells using TRI-Reagent. The primers tetherin-for (5' -CTGCAACCACACTGTGATG-3'), tetherin-rev (5'-ACGCGTCCTGAAGCTTATG-3'), 18 S rRNAfor (5'-TTCGGAACTGAGGCCATGAT-3'), and 18S rRNA-rev (5'-CGAACCTCCGACTTTCGTTT-3') were used. Expression levels of tetherin were normalized to one copy of 18S rRNA. Virus production was examined by real-time RT-PCR as described above.

\section{Results}

Cloning, sequence analysis and expression of tetherins of various species

Molecular cloning of the tetherin from different species was performed by RT-PCR using RNA extracted from 293T, MDCK, CRFK, NIH3T3, PK15, and FRhk cells. Fig. 1 shows the predicted amino acid sequence alignment of tetherin from different species. The amino acid sequence identities of tetherin among different species are relatively low (73.6\%-33.5\%). However, the 3 cysteine residues, which are involved in disulfide bond-linked dimerization of tetherin, are conserved among all species. Potential N-linked glycosylation sites are conserved as well (Fig. 1). As shown in Fig. 2, expression of tetherin variants in 293T cells were confirmed by Western blot analysis using an antibody against hemagglutinin (HA) tag. The HA tag allowed detection of the proteins in the cell lysates. 


\section{Cytoplasmic domain}

\section{TM domain}

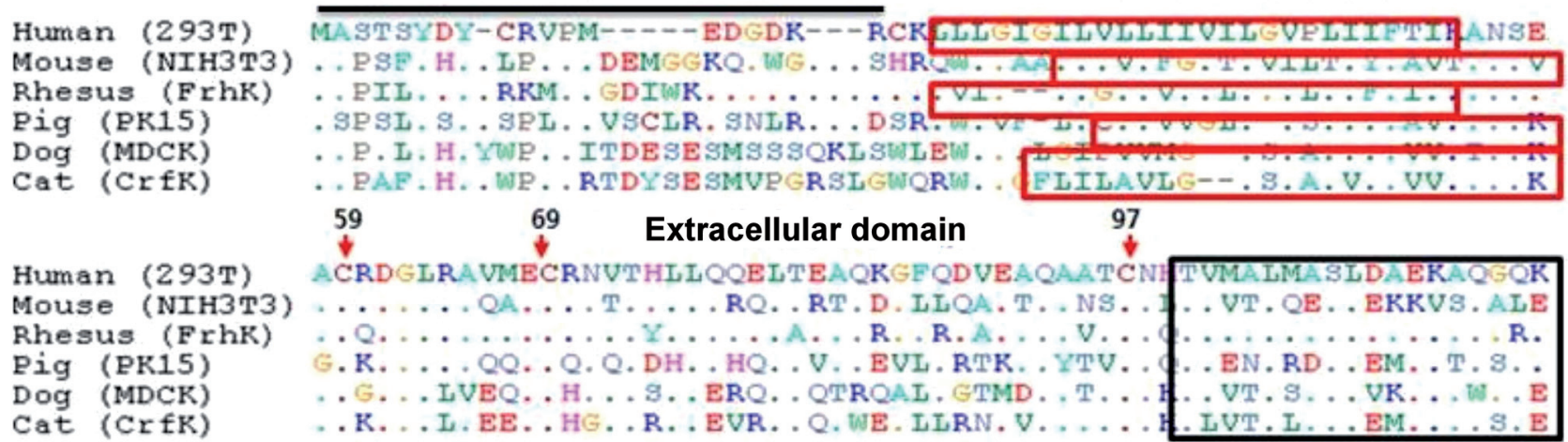

\section{Coiled-coil domain}

\begin{tabular}{|c|c|c|}
\hline $\begin{array}{l}\text { Human (293T) } \\
\text { Mouse (NIH3T3) } \\
\text { Rhesus (FrhK) } \\
\text { Pig (PK15) } \\
\text { Dog (MDCK) } \\
\text { Cat (CrfK) }\end{array}$ & 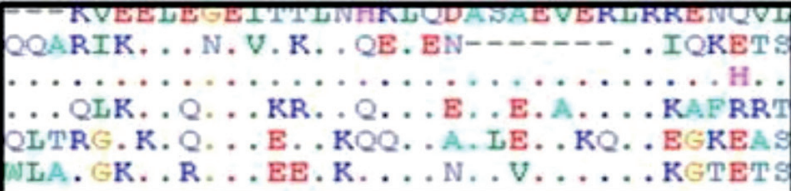 & 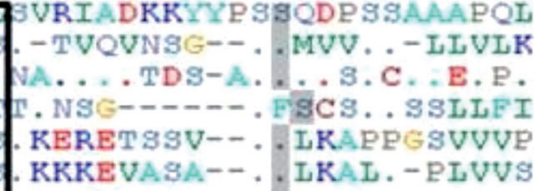 \\
\hline
\end{tabular}

\section{GPI}

\begin{tabular}{|c|c|c|}
\hline Human & (293T) & LIVLLGL SALLQ- \\
\hline Mouse & (NIH3T3) & USLF. LF ----.1 \\
\hline Rhesu & 3 (FrhK) & $\ldots L$ \\
\hline Pig & PR15) & \\
\hline Dog & MDCK) & VYL . . R R. \\
\hline & ER) & VHL . AFV \\
\hline
\end{tabular}

Fig. 1

Multiple alignment of amino acid sequences of tetherins of various species

The sequences were aligned against human tetherin using the Clustal W tool. TM and coiled-coil domains are boxed. The arrows mark predicted sites for cysteins. For Acc. Nos. of the sequences see Table 1.

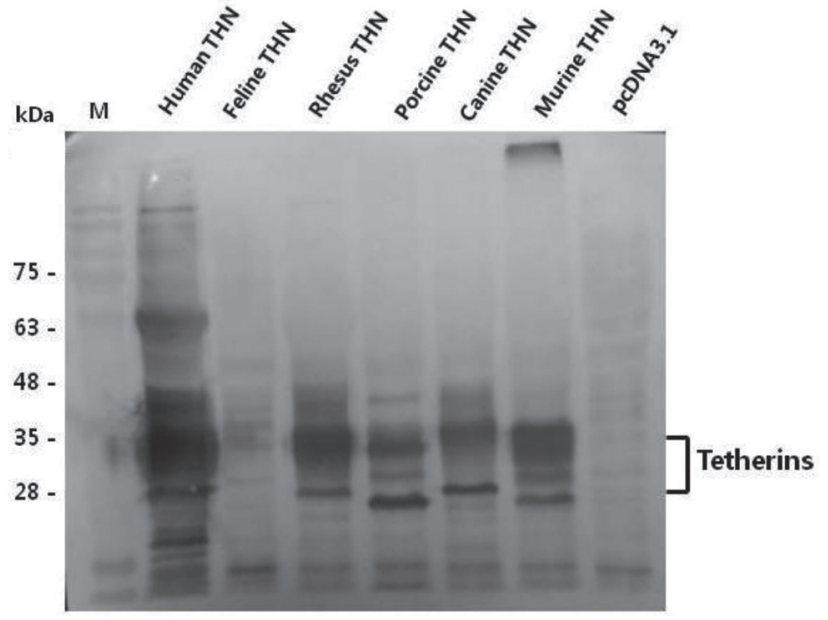

Fig. 2

Expression of tetherins of various species in 293T cells Western blot analysis of tetherins (THN) expressed in the cells $48 \mathrm{hr}$ post transfection with respective plasmids. Protein size markers (M), empty plasmid (pcDNA3.1).
Inhibition of release of PERV-VSV pseudotypes from cells by tetherins

PERV-VSV pseudotype coding for LacZ was produced by transfection of $293 \mathrm{~T}$ cells with tetherin plasmid. We assessed pseudotype virus titers by measuring their infection of 293T cells. Tetherin coding sequences from human, dog, feline, mouse, porcine, and rhesus macaque reduced PERV-A titers 12- to 63-fold in comparison to control plasmid. Similar to human tetherin, dog, feline, murine, porcine and rhesus macaque tetherins were equally efficient in reducing PERVVSV pseudotype yield (Fig. 3). Antiviral activity of murine and rhesus tetherin against PERV-VSV pseudotype release were slightly weaker than those of dog and feline tetherins.

\section{Inhibition of release of PERV from cells by tetherins}

To examine whether tetherin from different species has inhibitory activity against infectious PERV release, the expression plasmid for tetherin from different species was 
transfected into 293-PERV-PK-CIRCE cells and the amount of PERV in culture supernatant was demonstrated by realtime RT-PCR. Although all of the various tetherin species were equally efficient in reducing PERV, canine tetherin strongly inhibited PERV production (Fig. 4). These results show that exogenous expression of canine tetherin can be used to reduce PERV dissemination.

\section{Induction of tetherin in 293 T cells by IFN- $\alpha$}

It has been reported that IFN- $\alpha$ treatment induces the transcription of tetherin. To investigate whether the expression of human tetherin is induced by IFN- $\alpha$ and human tetherin has inhibitory activity against PERV release in human cells, we treated 293-PERV-PK-CIRCE cells with $250 \mathrm{U} / \mathrm{ml}$, $500 \mathrm{U} / \mathrm{ml}$, and $1,000 \mathrm{U} / \mathrm{ml}$ of IFN- $\alpha$ and analyzed the level of human tetherin mRNA by real time RT-PCR. In addition, PERV production was determined by real time RT-PCR assay. The 293-PERV-PK-CIRCE cells treated with IFN- $\alpha$ showed 20-40-fold increase in human tetherin mRNA level compared to untreated cells (Fig. 5a). This increase in human tetherin levels reduced PERV release from 293-PERV-PKCIRCE cells (Fig. 5b). These results show that IFN- $\alpha$ induction could enhance tetherin expression and suppress PERV release to the culture supernatant.

\section{Discussion}

Xenotransplantation is the transplantation of pig cells, tissues, and organs into human patients to relieve the shortage of human organs for donation (Magre et al., 2003). However, infection associated pig pathogens are a major concern in using porcine tissues for transplantation. Porcine endogenous retroviruses (PERVs) are of particular concern due to their capability of infecting human cells (Boneva et al., 2001). Although there is no evidence of PERV infection of humans in vivo, PERV have been shown to infect human cells in vitro. Strategies to reduce the PERV transmission have been proposed, such as selective breeding for lower levels of PERV, siRNA transgenesis to knock-down PERV expression, but those attempts are not effective and are expensive.

During mammalian evolution, a variety of mechanisms have arisen to limit retroviral replication. Retrovius replication can be restricted by cellular factors, such as APOBEC3G, Fv1, TRIM5a, and tetherin (Fukuma et al., 2011; Dietrich et al., 2011; Liberatore et al., 2011; Passerini et al., 2006; Sadler et al., 2010; Song et al., 2004). It appears that PERVs are insensitive to restriction by TRIM5a, but human APOBEC3G strongly restricts PERVs (Jonsson et al., 2007; Wood et al., 2009). In this study, we attempted to reduce PERV release during xenotransplantation by expressing restriction factor

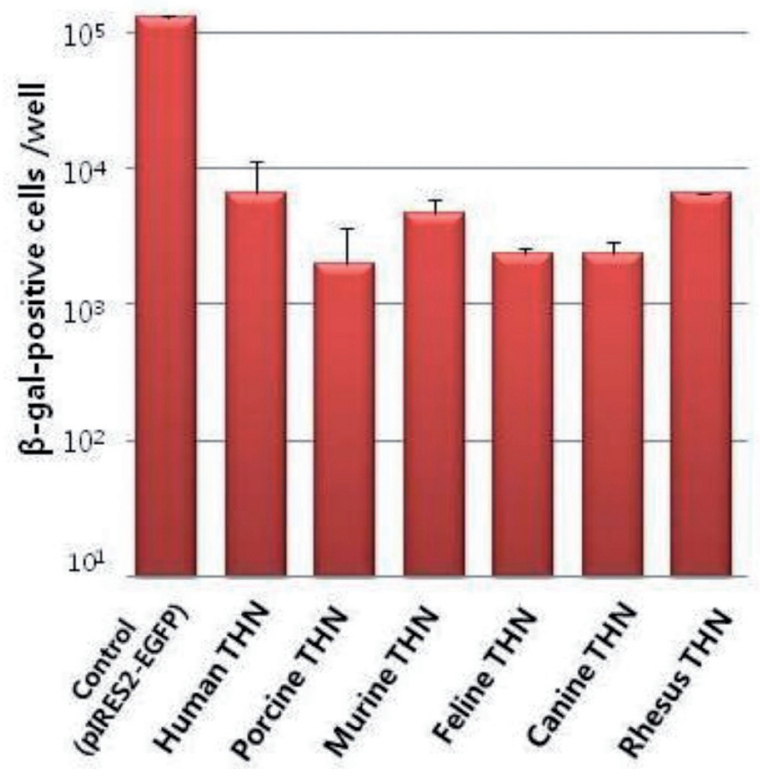

Fig. 3

Inhibition of release of PERV-VSV pseudotypes from 293T cells by tetherins of various species

The cells were transfected with two different plasmids expressing each of the pseudotype and respective tetherin and the supernatant was assayed 48 hrs later for the titer of PERV-VSV pseudotypes by staining with $\beta$-gal. Empty plasmid (pIRES2-EGFP) is used as control.

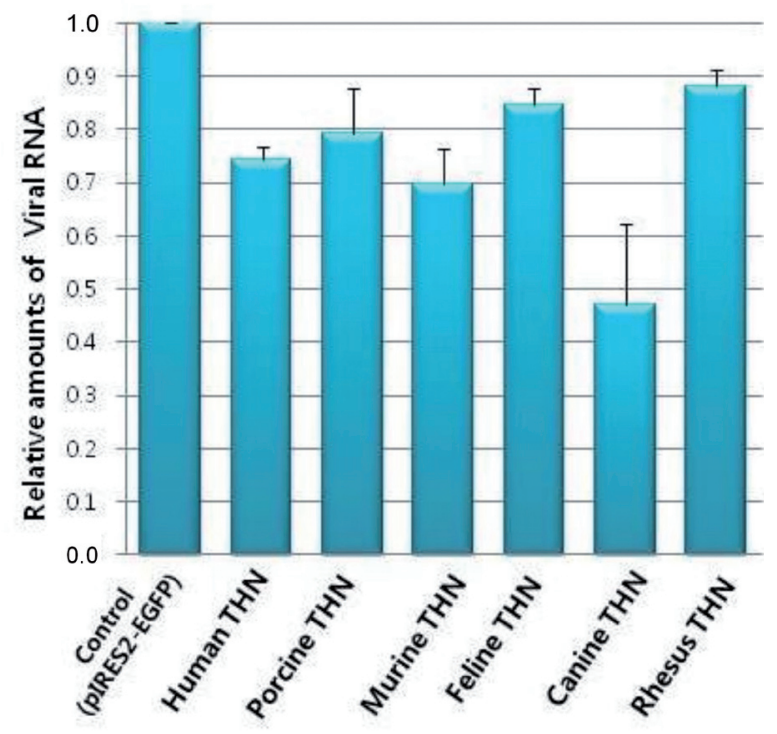

Fig. 4

Inhibition of release of PERV from PERV-harboring cells by tetherins of various species

293-PERV-PK-CIRCE cells were transfected with plasmids expressing various tetherins and the supernatant was assayed $48 \mathrm{hrs}$ later for PERV by real-time RT-PCR based on PERV gag gene. Empty plasmid (pIRES2EGFP) is used as control. 
tetherin in virus-producing human cells for developing a novel strategy to prevent PERV transmission.

Human and other mammalian tetherin sequences were amplified from suitable total RNA extracts by RT-PCR. Expression of tetherin variants in cell lysates was determined by Western blot. Tetherin signals are diffuse, due to heterogeneity in glycosylation with major signals in the range from 20-34 kDa. As compared to APOBEC3 and TRIM5a, sequence identities of tetherin from different mammalian species are relatively low. However, all the ectodomains of tetherins from different species contain 3 cysteines that participate in intermolecular disulfide bonds to form homodimers. We found that tetherin from different species inhibited the release of PERV from 293T cells based on a single-cycle assay. These data indicate that dimerization of tetherin is important for its antiviral activity.

It has been reported that although the release of Ebola and influenza virus VLP (virus-like particle) are restricted by tetherin, infectious Ebola and influenza viruses are not restricted by tetherin (Radoshitzky et al., 2010; Watanabe et al., 2011). These observations suggest that Ebola and influenza viruses might encode a tetherin antagonist. To investigate whether mammalian tetherin inhibits PERV replication in a spreading infection as efficiently as pseudotype assay, virus spread was monitored by real-time RT-PCR of the culture supernatant. The expression plasmid for tetherin from different species was transfected into 293-PERV-PK-CIRCE cells. In agreement with pseudotype assay, mammalian tetherins inhibit PERV replication in a spreading infection. In contrast to the marked inhibitory effect of tetherin from different species in pseudotype assays, tetherins from different species showed a weaker antiviral activity. It is possible that the presence of trapped virions at the cell surface promote cell-cell spread. Recently, it was reported that the cellcell spread of HIV-1 and FIV (feline immunodeficiency virus) overcomes tetherin-mediated restriction (Dietrich et al., 2011; Jolly et al., 2010). Antiviral activity of canine tetherin showed slightly greater effects than other mammalian tetherins in our real-time RT-PCR assay. These observations indicate that exogenous expression of canine tetherin may be useful as a novel strategy to reduce PERV release.

To test whether human tetherin can reduce PERV release from 293-PERV-PK-CIRCE cells by induction, we first investigated whether expression of human tetherin is induced by IFN- $\alpha$, and then examined the effect of IFN- $\alpha$ on PERV production in 293-PERV-PK-CIRCE cells. We found that human tetherin was IFN- $\alpha$ inducible and IFN- $\alpha$ treatment of 293-PERV-PK-CIRCE reduced PERV release. (a)

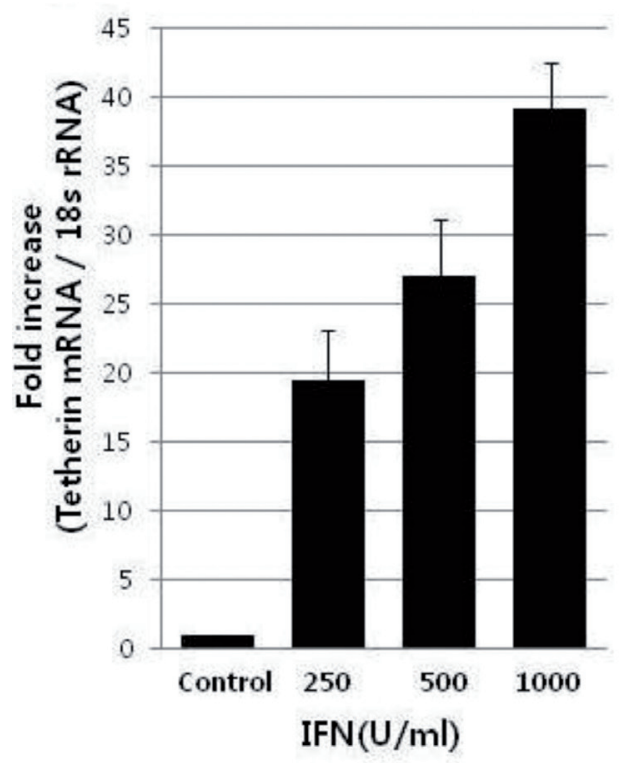

(b)

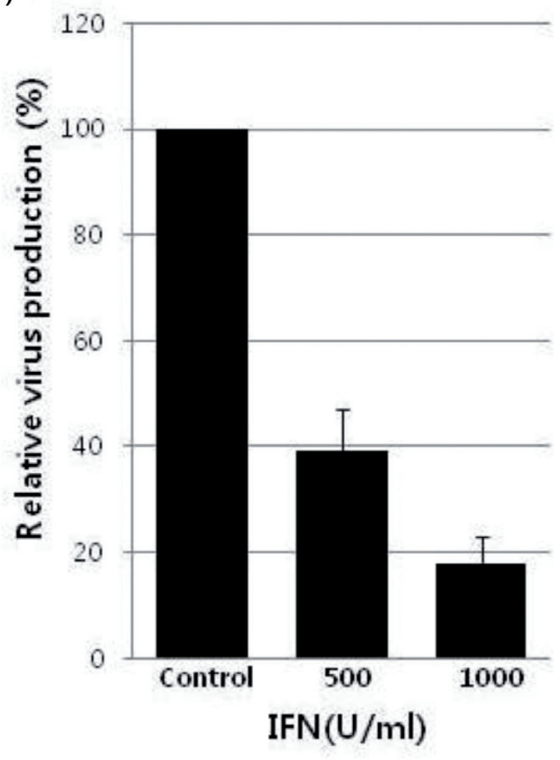

Fig. 5

Induction of tetherin and inhibition of release of PERV-VSV pseudotypes from PERV-harboring cells by IFN-a 293-PERV-PK-CIRCE cells were treated with various concentrations of IFN- $a$ for $24 \mathrm{hr}$ and the number of human tetherin mRNA copies was assayed by real-time RT-PCR (a) and for PERV by real-time RT-PCR based on PERV gag gene (b). 
In conclusion, both the induction of tetherin and transgenic overexpression of tetherin may reduce PERV dissemination in xenotransplantation.

Acknowledgements. This work was supported by the Basic Science Research Program through the National Research Foundation of Korea (NRF) funded by the Ministry of Education, Science and Technology (2010-0024912).

\section{References}

Boneva RS, FolksTM, Chapman LE (2001): Infectious disease issues in xenotransplatation. Clin. Microbiol. Rev. 14, 1-14. http://dx.doi.org/10.1128/CMR.14.1.1-14.2001

Dieckhoff B, Karlas A, Hofmann A, Kues WA, Petersen B, Pfeifer A, Niemann HR, Denner KJ (2007): Inhibition of porcine endogenous retroviruses (PERVs) in primary porcine cells by RNA interference using lentiviral vectors. Arch. Virol. 152, 629-634. http://dx.doi.org/10.1007/s00705-006-0868-y

Dietrich I, Hosie MJ, Willett BJ (2011): The role of BST2/tetherin in feline retrovirus infection. Vet. Immunol. Immunopathol. 143, 255-264. http://dx.doi.org/10.1016/j. vetimm.2011.06.020

Dietrich I, McMonagle EL, Petit SJ, Vijayakrishnan S, Logan N, Chan CN, Towers GJ, Hosie MJ, Willett BJ (2011): Feline tetherin efficiently restricts release of feline immunodeficiency virus but not spreading of infection. J. Virol. 85, 5840-5852. http://dx.doi.org/10.1128/JVI.00071-11

Fukuma A, Abe M, Morikawa Y, Miyazawa T, Yasuda J (2011): Cloning and characterization of the antiviral activity of feline tetherin/BST-2. PLoS One 6, e18247. http://dx.doi. org/10.1371/journal.pone.0018247

Harris RS, Liddament MT (2004): Retroviral restriction by APOBEC proteins. Nature 4, 868-877.

Jia B, Serra-Moreno R, Neidermyer WN, Rahmberg A, Mackey J, Fofana IB, Johnson WE, Westmoreland S, Evans DT (2009): Species-specific activity of SIV Nef and HIV-1 $\mathrm{Vpu}$ in overcoming restriction by tetherin/BST2. PLoS Pathog. 5, e1000429. http://dx.doi.org/10.1371/journal. ppat.1000429

Jolly C, Booth NJ, Neil SJ (2010): Cell-Cell Spread of human immunodeficiency virus type 1 overcomes tetherin/BST-2mediated restriction in T cells. J.Virol. 84, 12185-12199. http://dx.doi.org/10.1128/JVI.01447-10

Jónsson SR, LaRue RS, Stenglein MD, Fahrenkrug SC, Andrésdóttir V, Harris RS (2007): The restriction of zoonotic PERV transmission by human APOBEC3G. PLoS One 12, 2:e893.

Kaletsky RL, Francica JR, Agrawal-Gamse C, Bates P (2009): Tetherin-mediated restriction of filovirus budding is antagonized by the Ebola glycoprotein. Proc. Natl. Acad. Sci. USA 106, 2886-2891. http://dx.doi.org/10.1073/ pnas.0811014106

Kirchhoff F (2010): Immune evasion and counteraction of restriction factors by HIV-1 and other primate lentivruses. Cell
Host Microbe 22, 55-67. http://dx.doi.org/10.1016/j. chom.2010.06.004

Lee YJ, Park SH, Bae EH, Jung YT (2012): Characterization of molecular clones of porcine endogenous retrovirus-A containing different numbers of $\mathrm{U} 3$ repeat boxes in the long terminal repeat region. J. Virol. Methods 181, 103-108. http://dx.doi.org/10.1016/j.jviromet.2012.01.023

Le Tortorec A, Willey S, Neil SJ (2011): Antiviral inhibition of enveloped virus release by tetherin/BST-2: Action and counteraction. Viruses 3, 520-540. http://dx.doi. org/10.3390/v3050520

Liberatore RA, Bieniasz PD (2011): Tetherin is a key effector of the antiretroviral activity of type 1 interferon in vitro and in vivo. Proc. Natl. Acad. Sci. USA 108, 18097-18101. http:// dx.doi.org/10.1073/pnas.1113694108

Magre S, Takeuchi Y, Bartosch B (2003): Xenotransplantation and pig endogenous retroviruses. Rev. Med. Virol. 13, 311-329. http://dx.doi.org/10.1002/rmv.404

Mansouri M, Viswanathan K, Douglas JL, Hines J, Gustin J, Moses AV, Fruh K (2009): Molecular mechanism of BST-2/Tetherin downregulation by K5/MIR2 of Kaposi's sarcomaassociated herpesvirus. J. Virol. 83, 9672-9681. http:// dx.doi.org/10.1128/JVI.00597-09

Mattiuzzo G, Ivol S, Takeuchi Y (2010): Regulation of porcine endogenous retrovirus release by porcine and human tetherins. J. Virol. 84, 2618-2622. http://dx.doi.org/10.1128/ JVI.01928-09

McNatt MW, Zang T, HatziioannouT, Bartlett M, Fofana IB, Johnson WE, Neil SJD, Bieniasz PD (2009): Speciesspecific activity of HIV-1 vpu and positive selection of tetherin transmembrane domain variants. PLoS Pathog 5, e1000300. http://dx.doi.org/10.1371/journal. ppat. 1000300

Nakayama EE, Shioda T (2010): Anti-retroviral activity of TRIM5 $\alpha$. Rev. Med. Virol. 20, 77-92. http://dx.doi.org/10.1002/ $\underline{\text { rmv.637 }}$

Neil SJ, SandrinV, Sundquist WI, Bieniasz PD (2007): An interferon- $\alpha$-induced tethering mechanism inhibits HIV-1 and Ebola virus particle release but is counteracted by the HIV-1 vpu protein. Cell Host Microbe 13, 193-203. http://dx.doi.org/10.1016/j.chom.2007.08.001

Neil SJ, Zang T, Bieniasz PD (2008): Tetherin inhibits retrovirus release and is antagonized by HIV-1 vpu. Nature 451, 425-430. http://dx.doi.org/10.1038/nature06553

Passerini LD, Keckesova Z, Towers GJ (2006): Retroviral restriction factors Fv1 and TRIM5 $\alpha$ act independently and can compete for incoming virus before reverse transcription. J. Virol. 80, 2100-2105. http://dx.doi.org/10.1128/ JVI.80.5.2100-2105.2006

Perez-Caballero D, Zang T, Ebrahimi A, McNatt MW, Gregory DA, Johnson MC, Bieniasz PD (2009): Tetherin inhibits HIV-1 release by directly tethering virions to cells. Cell 139, 499-511. http://dx.doi.org/10.1016/j.cell.2009.08.039

Radoshitzky SR, Dong L, Chi X, Clester JC, Retterer C, Spurgers K, Kuhn JH, Sandwick S, Ruthel G, Kota K, Boltz D, Warren T, Kranzusch PJ, Whelan SP, Bavari S (2010): Infectious Lassa virus, but not filoviruses, is restricted by 
BST-2/tetherin. J. Virol. 84, 10569-10580. http://dx.doi. org/10.1128/JVI.00103-10

Sadler HA, Stenglein MD, Harris RS, Mansky LM (2010): APOBEC3G contributes to HIV-1 variation through sublethal mutagenesis. J. Virol. 84, 7396-7404. http:// dx.doi.org/10.1128/JVI.00056-10

Sakuma T, Sakurai A, Yasuda J (2009): Dimerization of tetherin is not essential for its antiviral activity against Lassa and Marburg viruses. PLoS One 4, e6934. http://dx.doi. org/10.1371/journal.pone.0006934

Sliva K, Resch T, Kraus B, Goffinet C, Keppler OT, Schnierle BS (2012): The cellular antiviral restriction factor tetherin does not inhibit poxviral replication. J. Virol. 88, 18931896. http://dx.doi.org/10.1128/JVI.05198-11

Song BW, Javanbakht H, Perron M, Park DH, Stremlau M, Sodroski J (2004): Retrovirus restriction by TRIM5 a variants from old world and new world primates. J. Virol. 79, 3930-3937. http://dx.doi.org/10.1128/JVI.79.7.3930-3937.2005
Viswanathan K, Smith MS, Malouli D, Mansouri M, Nelson JA, Fruh K (2011): BST2/Tetherin enhances entry of human cytomegalovirus. PLoS Pathog. 7, e1002332. http://dx.doi. org/10.1371/journal.ppat.1002332

Watanabe R, Leser GP, Lamb RA (2011): Influenza virus is not restricted by tetherin whereas influenza VLP production is restricted by tetherin. Virology 417, 50-56. http://dx.doi. org/10.1016/j.virol.2011.05.006

Wood A, Webb BLJ, Bartosch B, Schaller T, Takeuchi Y, Towers GJ (2009): Porcine endogenous retroviruses PERV A and $\mathrm{A} / \mathrm{C}$ recombinant are insensitive to a range of divergent mammalian TRIM5 $a$ proteins including human TRIM5a. J. Gen. Virol. 90, 702-709. http://dx.doi.org/10.1099/ vir.0.007377-0

Zhang J, Liang C (2010): BST-2 diminishes HIV-1 infectivity. J. Virol. 84, 12336-12343. http://dx.doi.org/10.1128/ IVI.01228-10 